\title{
LITERATUROZNAWSTWO
}

\author{
OKSANA WERETIUK
}

\section{Англофонный диптих о России и русских Вирджинии Вулф и Джона Стейнбека}

\section{The anglophone diptych about Russia and Russians: Virginia Woolf, John Steinbeck}

\begin{abstract}
The paper deals with the reception of the Russian character (mind and soul) by two prominent anglophone writers: Virginia Woolf and John Steinbeck. Virginia Woolf recognizes the Russians and their soul through the perception of the great Russian masterpieces of Tolstoy, Dostoevsky, and Chekhov (The Russian Point of View, essay, 1925); Steinbeck's A Russian Journal, 1948, presents the Russians as they were observed by the American author in their everyday life, rebuilding their country after WWII. The genre specificity of each work, the differences of time, emotions and purpose of writing, the Russian "experience" of each author, determine a certain heterogeneity of understanding of Russia and Russians; nevertheless, both form a heterogeneous whole of the Anglophone perception.
\end{abstract}

Keywords: Russian character, Russian soul, Russian mind, Woolf, Steinbeck

Oksana Weretiuk, Uniwersytet Rzeszowski, Rzeszów - Polska, oksanaw@ur.edu.pl, ORCID ID: https://orcid.org/0000-0001-9532-3264

На материале двух разножанровых англоязычных произведений - эссе The Russian Point of View (1925) Вирджинии Вулф и очерков A Russian Journal (1948) Джона Стейнбека - предпринимается попытка воссоздания англо-американской литературной перцепции становой жилы русского характера - русской души и ума. Жанровая специфика каждого произведения, разница во времени и целях написания, русский „опыт” их авторов и др. обуславливают определенную неоднородность понимания России и русских, тем не менее образуют гетерогеническую целость англофонной перцепции.

Сердце и душа Блумсбери, Вулф (1882-1941), заинтересованная русской литературой, изучает русский язык, чтобы лучше понять ее дух. Россию, 
русских английская писательница познает из британских исторических источников, в том числе путевых документов елизаветинских времен (см. Protopopova 2006: 4-6), читая современную прессу, освещающую русский вопрос, но прежде всего, через русскую литературу с ее образными художественными мирами и яркими персонажами. Русские герои общаются между собой, рассуждают, страдают и радуются, жестикулируют, действуют или смиренно несут свой жребий - все это помогает ей познать их отличительное поведение. Заинтересованность русской темой проявилась в раннем периоде творчества Вулф и, вероятно, связана с общим вниманием английской и западной общественности ко всему русскому во время Первой мировой войны - в годы, когда, по словам Рональда Хингли (Hingley 73), „эпидемия культурной русомании охватила весь мир"1. Английский исследователь из Оксфорда, вероятно, имел в виду тогдашнюю одержимость Россией и всем русским, безудержное, отчасти неосознанное стремление британцев к русскому искусству (ср. Beasley, Bullock 1-18; Beasley 28-33, 440; Bullock 113128). Сверстница Вулф, молодая интеллектуалистка и журналистка Ребекка Вэст, в январе 1915 г. смело заявила в печати: „Россия для сегодняшних молодых интеллектуалистов стала тем, чем была Италия для викторианцев” (цит. по: Beasley, Bullock 18). Не могла не затронуть интеллектуальных потребностей молодой писательницы русомания или русофилия, нередко понимаемые синонимично (см. Rubenstein 1-16; Protopopova 2019: 16-19). Русофилия в Британии наблюдалась уже перед войной, как более сдержанная и осознанная позиция, заключавшаяся в заинтересованности и благоприятном отношении к россиянам и всему, что является русским. Роберта Рубенстайн, американская исследовательница английского модернизма, объясняет „русский” энтузиазм Вулф, проявившийся в Орландо (Orlando, 1928), в контексте британской послевоенной русофилии, „коллективного восторга, проявляемого не только по отношению к русской литературе, но и другим видам искусства, и прежде всего, к изобразительному искусству, музыке, балету", - и вместе с тем, подытоживая вышесказанное, определяет образно этот восторг как „русский «пункт помешательства» в Англии” („the Russian «craze» in England") (Rubenstein 15), мания и повальное увлечение.

Наталья Рейнгольд, русская исследовательница творчества Вулф, упоминая семнадцать литературно-критических эссе английской модернистки о русских писателях, опубликованных в английской периодической печати в 1917-1933 гг., десятки комментариев и высказываний о произведениях русских писателей в других эссе, дневниках и письмах, повесть Собственная комната (A Room of One's Own, 1929) и роман Орландо, намечает несколько

\footnotetext{
1 Здесь и далее перевод с английского мой, если не указан кто-то другой.
} 
аспектов изучения русской тематики в литературном наследии английской модернистки, в том числе:

[...] историко-литературный, связанный с изучением биографии Вулф в контексте англо-русских литературных и общекультурных связей 1910-1930-х гг.: рецептивный, исследующий деятельность Вулф, литературного критика, читателя, комментатора русской литературы; переводоведческий, обращенный к анализу переводов с русского языка, выполненных Вулф совместно с С. С. Котельянским (1880-1955); текстологический, посвященный анализу рукописных и машинописных вариантов произведений Вулф на русскую тему; наконец, собственно литературоведческий, сосредоточенный на анализе художественного образа России и русских в романе „Орландо” (1928) (Rejngol’d).

По моему мнению, рецептивная тематика эссе The Russian Point of View начертила контуры для рассмотрения его имагологических свойств. Писательница, литературный критик, проницательный комментатор русской литературы, Вулф познавала Россию по произведениям русских писателей, поэтому столь важным для нее было знание языка оригинала. С чувством недовольства констатирует она существование „мощного языкового барьеpa” (Woolf, электронный ресурс), не позволяющего познать русское. С нескрываемой иронией осуждает критиков и интерпретаторов Льва Толстого, Федора Достоевского и Антона Чехова, „которые за последние двадцать лет были не в состоянии прочитать их произведения в их родном языке”, а судили о художественном достоинстве, „слепо и безгранично подчиняясь” переводу, и чаще всего, не английскому, а с третьей руки. Автор эссе весьма категорична по отношению к переводам, их неизбежной ограниченности: „Мы выражаем мнение о литературе, полностью лишенной своего собственного стиля" (Woolf, электронный ресурс). Особенно не удовлетворяют Вулф буквальные переводы, препятствующие адекватному восприятию русского и русских.

Если переводится каждое слово в предложении с русского языка на английский, изменяются при этом некоторым образом смысл и звучание, вес и акцент слов, полностью разрушая отношения между ними. Таким образом, не остается ничего, кроме грубой, примитивной версии смысла. Отсюда следующий вывод: великие русские писатели похожи на людей, лишенных вследствие землетрясения или железнодорожного происшествия не только всей своей одежды, но и чего-то более тонкого и более важного - своих манер, особенностей характера (Woolf, электронный ресурс).

Вместе с мужем, писателем Леонардом Вулфом, романистка и критик брала уроки русского языка у украинского эмигранта Самуила Самойловича Костелянского в целях лучшего понимания сокровенно русского - в вымышленных мирах и наяву. Переводчик, издатель, критик и популяризатор русской литературы в Британии, Костелянский привлекал молодую англий- 
скую писательницу к работе над переводами Чехова, Достоевского, Толстого и Максима Горького. Таким образом, находясь между двумя мирами - своим и чужим, соприкасаясь с каждым из них, Вулф как переводчик осваивала неведомое, приближала Россию Британии. Постигала специфику русских естественно через персонажей прочитанных произведений. Открывая книгу, она „открывала дверь и оказывалась в комнате, полной русских генералов, наставников русских генералов, их падчериц и двоюродных сестер, а также толп разных людей, которые все говорили своими голосами о своих самых личных делах" (мной перефразирована грамматическая форма оригинала O.W) (Woolf, электронный ресурс). Старалась понять их не разумом, а сердцем - их печаль, их бунт, их страдание.

Простота, отсутствие усилий, предположение о том, что в мире, разрывающемся от страданий, главный призыв к нам состоит в том, чтобы понять наших собратьев по несчастью, „но не умом - потому что это легко умом - а сердцем” (Вулф, вероятно, цитирует д-pa Hagberg Wright - O. W.) - это облако, которое парит над всей русской литературой, отвлекает нас от нашего собственного потускневшего глянца и выжженных путей, чтобы разрастись в его тени [...] (Woolf, электронный ресурс).

Вероятнее всего, понять страдание „не умом, а сердцем” для эссеистки было равнозначно жалости, сочувствию, состраданию, соучастию в перетерпении бремени несчастья. Языковед Ирина Левонтина подробно описала значение синонимических русских названий этих эмоций (Levontina 2003: 327-331). Ссылаясь на исследования других лингвистов, и прежде всего Анны Вежбицкой (Wierzbicka), она резюмирует:

Хорошо известно, насколько важным для русской культуры является чувство жалости; [...] Склонность к жалости (жалостливость, сердобольность) осознается как специфически русская черта, поэтому чрезвычайно типичны сочетания русская жалость, русская жалостливость, русская сердобольность, по-русски жалостливый и т. п. [...] Причем и те, кто считает это чувство прекрасным, и те, кто низко его оценивает, сходятся в одном: предрасположенность к этому чувству типична для русского человека, „русской души" (Levontina 2005: 270).

Простота, доброта, сердечность, отзывчивость, сострадание, душевность русских наиболее привлекают Вулф и становятся для нее отличительными ориентирами русского языкового мира ${ }^{2}$, русской литературы и чертами на-

${ }^{2}$ Не располагаю источниками, подтверждающими факт чтения Вирджинией Вулф фундаментальных работ Вильгельма фон Гумбольдта по философии языка, но ее подход к языку при переводе совпадает с его концепцией национального содержания языка и мышления (Humboldt 324), положившей начало современным теориям языковой картины мира. 
ционального характера и мировоззрения народа в целом (см. Losskij 68-70; Solov'ev; Stepanov; Šmelev, Levontina 2005).

Особенно близким ее восприятию был Чехов. Удивляет писательницу пассивность, бездеятельность, покорность судьбе его персонажей (русский характер?). Тут же замечает, что для них (персонажей) главным являются не интеллектуальные достижения, а величие души: „Читая Чехова, мы снова и снова повторяем слово «душа». Оно прямо брызжет, струится из страниц. Старые пьяницы используют его свободно; «[...] ты высоко в службе, вне всякой досягаемости, но у тебя нет настоящей души, мой дорогой мальчик [...] не в этом мощь»" (Woolf, электронный ресурс). Вулф понимает, что, высказывая свое мнение о человеке, русские прежде всего говорят о его душе или сердце, а не о его уме (mind) и интеллекте (intelligence/intellect). Критик приходит к ключевому выводу: „Действительно, именно душа - главный герой русской художественной литературы”.

Верно, понятие „душа” настолько важно в ментальности и мировосприятии русских, что отнесено к концептам ценностей их культуры и стержневым словам русской языковой картины мира, существующим также в других культурах, „но особенно значимым именно для русской культуры и русского сознания" (Šmelev 30). Лингвист относит к ключевым такие слова, как cyдьба, душа, жалость и некоторые другие. По его словам,

слово душа широко используется не только в религиозных контекстах - душа понимается как средоточие внутренней жизни человека, как самая важная часть человеческого существа. [...] Если бы мы говорили по-английски, упоминание души в [...] (некоторых) случаях было бы неуместно. Не случайно мы иногда используем выражение „русская душа” [...], но никогда не говорим об „английской душе” или „французской душе” (Šmelev 30).

В свою очередь Юрий Степанов, предпринявший попытку систематизации концептов („,констант”) в духовной культуре россиян, наряду с константами „Правда”, „Закон”, „Любовь”, „Вера”, „Сущность”, „Слово” и др., описал константу „Душа” (Stepanov 369-572, 736-740) как тесно связанную с упомянутыми выше. Российский (а ранее советский) лингвист возвращается к истокам русской духовности и ментальности - учению Феодора, пресвитера Раифского, о сущности, мудрости и души. Для византийского богослова

[...] не тело находится в форме, но форма в теле, ибо тело есть сущность, а форма - случайное. Подобно в случае души и мудрости: не душа пребывает в мудрости, но мудрость в душе. Поэтому и не говорится: тело формы и душа мудрости, но: форма тела и мудрость души. Душа тем самым есть сущность, а мудрость - случайное. При упразднении души упраздняется мудрость, при упразднении же мудрости душа не упраздняется (цит. по: Stepanov 150). 
Вулф, ставившая под сомнение христианское вероисповедание (она отвергла традиционные представления о Боге, провозглашая себя атеисткой; см. Nicolson, Trautman 52, 149), сосредотачивается не на религиозном значении жалости, сострадания, души, а на психологическом, моральном, последнее же - независимо от убеждений критика - в большой степени связано с христианской византийской культурой, „с представлением о смирении, о любви к слабому человеку, о том, что гордость это зло и т. п.” (Levontina 2003: 330). Не один иностранец замечал эту особенность русских, но молодая английская писательница одна из первых описала ее на персонажах русской литературы. По мнению Рубенстайн, Морис Беринг, британский романист и критик, еще раньше, в 1910 г., в своей книге под названием Landmarks in Russian Literature поставил задачу выявления доминантных национальных особенностей русского персонажа (характера) (Rubenstein 2). Несмотря на избыточный эмоциональный стиль автора, часто нарушающий чтение ее мыслей и утрудняющий их понимание, эссе и сегодня не потеряло своего значения. Много лет спустя, соотечественник Вулф, Рональд Хингли, исследуя русский склад ума, вспоминает былую модернистическую заинтересованность русской душой:

Русская душа больше не является целью беспорядочного восхищения, чем она когда-то была. Этот спад совсем не удивляет, поскольку точные статистические данные свидетельствуют о том, что с 1918 года в России на пятьдесят процентов снизилось употребление слова душа. Но эта концепция, не дождавшись своего определения, была очень модной на Западе во время Первой мировой войны - в годы, когда эпидемия культурной русомании охватила весь мир. В этот период в Лондоне был опубликован иллюстрированный сборник статей The Soul of Russia (Душа России) как помощь для русских беженцев, и эта концепция очень повлияла на английских критиков и писателей этого периода (Hingley 72-73).

В качестве примера автор приводит Вулф с ее неповторимым определением души как главного персонажа русской литературы. После 1928 г. ее заинтересованность Россией, русской литературой иссякла (см. Reinhold 1-27; Rejngol'd), но запечатлелось навсегда обращение молодой писательницы к России как к поэтическому образу, стране великих творцов и людей с особенным пониманием души, способных сочувствовать и сопереживать.

Совсем иная тональность изложения и направление мыслей о России у Джона Стейнбека (1902-1968). В отличие от Вулф, познававшей Россию из печатного слова, Стейнбек-писатель навестил СССР три раза: в 1937, 1947, 1963 годах. Особенно плодотворной и познавательной оказалась его наиболее продолжительная, сорокадневная, поездка в СССР в 1947 г., которую он совершил вместе с известным фотографом, американским евреем венгерско- 
го происхождения Робертом Капой (Андре Фридман). С 31 июля до середины сентября они посетили Москву, Киев, Сталинград, Тбилиси и Батуми, став одними из первых американцев, побывавших во многих уголках СССР со времен социалистической революции. Очерки писателя о поездке в СССР сначала публиковались в газете „New York Herald Tribune”, а затем вышли отдельной книгой под названием Русский дневник (A Russian Journal, 1948). Книга Стейнбека была проиллюстрирована высоко профессиональными фотографиями Капы. Как в Италии, Франции и других западных странах, в России писатель сфокусировал свое внимание на простом труженике, при этом пытался абстрагироваться от всяких политических полемик, споров, старался быть правомерным судьей происходящих событий. Автор романа Гроздья гнева (The Grapes of Wrath, 1939), осуждающего собственное капиталистическое общество, воспринимался в России как „свой писатель”, „союзник по классовой борьбе” (Glotov, Kolesnikova 30-31), тем не менее подготовка, как и само путешествие, происходят под бдительным надзором КГБ (Benson 108, 598, 929, 957), а опубликованный впоследствии Русский дневник, по словам самого Стейнбека, „правдивый, откровенный репортаж” (см. Šillinglou 1), знаменующий заключительную часть его военной журналистики, поддавался активной критике в бывшем СССР.

Весной 1947 г. газета „New York Herald Tribune” предложила Стейнбеку и Капе осуществить поездку и издать книгу репортажей, путевой дневник, они сделали собственно то, что обещали: „Это рассказ не о России, а о нашей поездке в Россию" (Stejnbek 8). Во время холодной войны, взаимных обманов и искажений, усиленной русофобии в США Стейнбек поставил на правду: решил написать, по его словам, „подробный отчет о поездке. Путевой дневник” (Stejnbek 8) и тем самым помочь обоим народам. У писателя было много предшественников с их собственным русским опытом и идеологическими устремлениями. Несмотря на общее враждебное отношение Западного мира к „Стране Советов” после октябрьской революции 1917 г., в США в 20-30-е гг. „поколение американцев выбралось в Советский Союз в поисках творческого вдохновения, а также чтобы найти конкретные лекарства на излечение проблем, которые вырисовывались и казались почти неразрешимыми в их собственном обществе" (Feuer, цит. по: Hollander 105). Поль Холландер детально прослеживает паломнический путь в СССР многих искателей во время насильственной коллективизации, голода, террора и показательных судебных процессов 30-х годов, когда они разубедились в утопии совершенного советского общества, что и запечатлели в своих публикациях. Их описания России были весьма отрицательные. Много отрицательных черт русских найдем в воспоминаниях коллеги Стейнбека, как и он, писателя и корреспондента той же „New York Herald Tribune” и „New 
York Times", Вилльяма Чепмена Вайта, посетившего СССР в 30-е гг. (White). После войны Стейнбек посчитал уместным воздержаться в своих сочинениях от эмоций, предрассудков и политических окрасок. „Мы должны постараться не критиковать и не хвалить, делать честные репортажи о том, что мы видели и слышали. Мы будем обходиться без редакционных комментариев и без выводов о том, что мы недостаточно хорошо знаем" (Stejnbek 8). Несмотря на то, что американский писатель не стремился создать полный имагологический образ русского ${ }^{3}$, некоторые характерные черты недавнего собрата по оружию, а в 1947 г. в глазах правительства Гарри Трумэна и большей части американцев - глобального геополитического, военного, экономического и идеологического врага - не укрылись под его внимательным взглядом. Путевые очерки зрелого, уравновешенного писателя крайне отличаются от молодой, изливающейся восторженности Вулф. Сдержанная наррация американского автора работает на эмоции читателя, как заметил Владимир Познер: „Своим поразительно точным глазом Стейнбек фиксирует абсолютно все - фиксирует как будто бесстрастно, но на самом деле так, что вызывает у читателя самые разные эмоции - удивление, смех и, да, слезы” (Pozner 1). Его описания послевоенной Москвы и Сталинграда настолько точны и детальны, что напоминают фотоснимки, впрочем, они как бы словесно дополняют документальные съемки Капы [,у фотоаппарата нет предубеждений, он просто регистрирует то, что видит" (Stejnbek 17)].

Поражает американского писателя отсутствие улыбки, смеха у москвичей, их усталость, даже в праздничные дни.

[...] на улицах почти не слышно смеха, а люди редко улыбаются. Люди ходят, вернее, торопливо шагают, понурив голову, - и они не улыбаются. Может быть, это происходит из-за того, что они много работают, или из-за того, что им далеко добираться до места работы. Так или иначе, на улицах царит ужасная серьезность. Может быть, так было здесь всегда - мы не знаем. Смеются в деревнях, на Украине, в степях, в Грузии, но Москва это очень серьезный город (Stejnbek 19-20).

Стейнбек очень осторожен в своих выводах, избегает обобщений, в том числе и имагологических - не распространяет замеченную у москвичей черту на весь русский народ, хотя, вероятно, знает, что его, западный, мир считает феномен угрюмости и неулыбчивости русских в ежедневной жизни одной из наиболее значимых невербальных черт их национальной характеристики. До Второй мировой войны в американской славистике, истори-

3 Это сделал британский писатель и переводчик, Эдвард Кренкшоу, одновременно со Стейнбеком предпринявший попытку „создать образ русского народа, его культуры, его политических идей на фоне неизменности ландшафта и климата" в книге Россия и русские (Crankshaw 3). 
ческой науке и интеллектуальных кругах уже выработался определенный стереотип русского национального характера, главным образом обоснованный спецификой ландшафта, природной среды, политическими факторами (см. Engerman 12-30; Holmgren 105-127). Сами русские сегодня объясняют свою „неулыбчивость” по отношению к посторонним своеобразием коммуникативной традиции (см. Prohorov, Sternin; Hingley 57). Стейнбек, избегая оценочного суждения о вышеупомянутой черте русских, тут же дает другой „снимок” - совершенно неприемлемого для США и Британии отношения русских к своему правительству (безграничное повиновение, скованность, страх перед ним).

[...] В Советском Союзе народ учат, что вождь - это хорошо и руководство всегда право. Аргументы тут бессильны [...] (Stejnbek 15).

В Советском Союзе ничто не происходит без пристального взгляда гипсового, бронзового, нарисованного или вышитого сталинского ока. [...] Надо думать, рисование, лепка, отливка, ковка и вышивание изображений Сталина являются в Советском Союзе одними из самых развитых отраслей. Он всюду, он все видит. Американцам с их страхом и ненавистью к делегированию власти одному человеку и к увековечиванию этой власти все это чуждо и представляется отвратительным. Во время публичных торжеств изображения Сталина вообще выходят за грани разумного. Они могут быть высотой с восьмиэтажный дом и достигать ширины пятьдесят футов (двадцать пять метров). Чудовищных размеров портреты Сталина висят на каждом общественном здании (Stejnbek 21-22).

Американский писатель, спрашивая встречных прохожих о причине такого помпезного и повсеместного изображения вождей правительства и партии, пытался найти объяснение этого русского феномена и получил несколько вариантов ответов.

Один из них заключался в том, что русский народ привык к изображениям царя и царской семьи, а когда царя свергли, его нужно было кем-то заменить. Другой ответ состоял в том, что образу мыслей русских свойственно поклонение иконам, а сталинские портреты и являются такими иконами. Третьи говорили, что русские так любят Сталина, что хотят, чтобы он существовал вечно. Четвертые утверждали, что Сталину самому все это не нравится и что он просил прекратить эту практику (Stejnbek 22).

Второй „снимок” молча объясняет предыдущий: можно ли встречать открытой улыбкой незнакомого, в частности чужестранца с Запада, находящегося под пристальным взглядом политико-государственного надзора, исторически всегда существовавшего в России?

Что касается русской ксенофобии, американский писатель не без скрытого юмора потверждает подмеченную ранее известным немецким путешественником, ученым-ориенталистом и запечатленную им на письме 
характерную боязнь русских к иностранцам, ничуть не изменившуюся с XVII века:

\begin{abstract}
„Русские очень подозрительно относятся к иностранцам; за последними постоянно надзирает тайная полиция. Она отслеживает каждый их шаг и докладывает о нем властям. Ко всем иностранцам приставлены агенты. Кроме того, русские не принимают иностранцев у себя дома и, похоже, боятся с ними даже разговаривать”. Написано в 1634 году! Это из книги Адама Олеария, которая называется „Описание путешествия в Московию и через Московию в Персию и обратно” (Stejnbek 57).
\end{abstract}

Зато ставит под сомнение стереотип о русском лентяйстве и безделии. В первые послевоенные годы русские (советские) труженики отличались исключительным героизмом при восстановлении разрушенных войной жилых зданий, учреждений, заводов. Особенно поразил американских корреспондентов героический дух сталинградцев. „Здесь, на заводе, который защищали его рабочие и где сейчас те же рабочие продолжали собирать трактора, можно было бы запечатлеть сам дух русской стойкости”, - утверждает Стейнбек. И тут же добавляет весьма важную деталь: „И почему-то именно здесь, где этот дух проявился с такой ошеломляющей силой, мы снова убедились в существовании страха перед фотоаппаратом" (Stejnbek 38), то есть перед незнакомым, а также страха быть „записанным, запечатленным” для возможного компрометирующего материала.

По мнению многих исследователей, лентяйство, пассивность и героизм, стойкость - это антиномичные черты русского народа. К примеру, Хинли через эти противоречия пытался разрешить сложную загадку русского ума: „Возможно, именно эта дихотомия, это самое противоречие между полной неактивностью и избытком активности, может дать первую подсказку для [разгадки] русского разума" (Hingley 17). Стейнбек, наблюдая, как заново русские люди отстраивали города, поселки и деревни, предприятия промышленности, железные дороги (ведь Советский Союз понес тяжелейшие потери в войне) при сохранении полувоенной дисциплины, мог только сказать: „Это очень правильные, высоконравственные, трудолюбивые люди [...]" (Stejnbek 42). Тем не менее, как и Хинли, признается в трудностях понимания логики русского ума человеком Запада. Впрочем, замечает Стейнбек и обратный процесс: непонимание русскими образа мыслей американца. На встрече с литературными деятелями писатель пытался как можно точнее и объективнее формулировать свои ответы в интервью, и чтобы убедиться, правильно ли его поняли, он позже попросил перевести эти ответы, переведенные на русский, обратно с русского на английский. В результате обнаружил полное непонимание его мыслей и предвидел долгий путь к взаимопониманию двух народов: 
[...] записанные ответы и близко не соответствовали тому, что я сказал в действительности. Это не было сделано специально, и дело здесь было даже не в трудностях перевода с одного языка на другой. Тут было нечто большее, чем языковые проблемы. Это была попытка перевода с одного образа мышления на другой. Наши собеседники были приятные и честные люди, но мы так и не смогли войти с ними в тесный языковой контакт. Это интервью стало последним - больше я подобных попыток не делал (Stejnbek 34).

Русский дневник заканчивается весьма оптимистически. Несмотря на разницу в мировосприятии, привычках и традициях двух народов, вопреки крайне враждебному идеологическому противостоянию государств, американский писатель и корреспондент сумел увидеть в русских - с их ошибками, перегибами, непонятным поведением и поступками - простых обычных людей, ненавидящих войну и, как все, жаждущих ,жить хорошо, со все большим комфортом, в безопасном мире” (Stejnbek 62). Поворот от русофобии к русофилии среди американцев наблюдается только под конец 1980-х. (см. America's Vogue for Things Russian, электронный ресурс). Союзничество во время Второй мировой войны вызвало кратковременное смягчение отрицательного отношения американцев к России, продолжавшееся до „холодной войны”. Стейнбек поймал и продлил эту волну, пытаясь быть объективным.

Сравнивая эссе увлеченной русской литературой - как большинство ее тогдашних соотечественников - молодой английской писательницы и серию репортажей, написанных для газеты жаждущим увидеть и понять людей, победивших гитлеровскую Германию, известным американским писателем и военным корреспондентом, наблюдаем различия в авторском восприятии России и русских. Возраст (молодость - зрелость), эмоциональное состояние (увлеченность - трезвое отстранение), собственный жизненный опыт (Россия книжная - Россия увиденная), исторический момент (русофилия холодная война), жанр (литературно-критическое эссе - путевые записки), задание, которое каждый автор ставил перед собой, создавая прозу о России Вулф: описать мастерство русских художников слова в портретировании русского человека, его стремлений, эмоционального состояния, его души; Стейнбек: понять и описать простого русского человека в празднике и в буднях, „понять русских крестьян, рабочих, рыночных торговцев” (Stejnbek 12), - все это способствовало расхождению двух художественных отображений страны и народа. Американский писатель хотел показать, что Россия чрезвычайно сложное государство, полное противоречий и проблем: помпезное представление правительства и более чем скромная, серая одежда граждан, даже у женщин „одежда опрятна, но не очень красива” (Stejnbek 17), разливающаяся энтузиастическая, оптимистическая музыка и угрюмые, унылые лица прохожих, радушное гостеприимство и настороженность по отношению к чужому, полное и беспрекословное подчинение своему пра- 
вительству, неравенство в распределении товаров, послевоенная бедность крестьян и рабочих и т. д., которые способствовали формированию своеобразного русского и советского характера, совершенно отличного от человека Запада. Для американцев и британцев, ценящих человеческую свободу, человеческую индивидуальность, режим советской власти был абсолютно неприемлем. Стейнбек, сознательно избегающий политического и исторического контекста, ограниченный в своем передвижении по СССР (был там, где позволили быть, видел то, что показывали) не мог не заметить и не запечатлеть этого в репортажах. Его поверхностный, селективный, состоящий как бы из отдельных увиденных и записанных фрагментов (принцип жалюзи) образ русских тем не менее оказывается точным и ярким. „Как это ни парадоксально, их [Капы и Стейнбека] подход - описывать только то, что видели сами - более точно отражает сталинский Советский Союз, где гости видели только сцены, тщательно срежиссированные советскими официальными лицами" (Šillinglou 5).

Вулф сосредоточилась на литературном изображении русских и познавательных чертах русских писателей (комментирует общественные, нравственные и философские взгляды Достоевского, Тургенева, Толстого, Чехова, Горького, дает свою оценку русскому искусству, литературе, свое понимание русской грусти, русской души). Ее молодой ум восторженно принимал Россию и ее литературу в контексте перемен после 1917 года, сразу не заметив скорого пришествия грозной поры, нивелирующей русского человека и его душу. Возможно, именно драматические события в советской России во второй половине 20-х и в 30-х гг. (на которые, кстати говоря, Вулф с негодованием реагировала - cм. Rejngol'd) способствовали угасанию интереса писательницы к русской теме.

Оба произведения являются свидетельствами западного понимания России и русских. Написанные с симпатией к так отличающемуся от их собственного народа, они не скрывают отрицательных черт русской жизни и наличия трудных, порой непреодолимых барьеров взаимного понимания народов.

\section{Библиография}

„America's Vogue for Things Russian”. New York Times, 19 October 1988, section C, s. 10. Web. 06.09.2019. https://www.nytimes.com/1988/10/19/garden/america-s-vogue-for-things-russian. html.

Beasley, Rebecca. Russomania: Russian Culture and the Creation of British Modernism, 18811922. Oxford, Oxford University Press, 2017. 
Beasley, Rebecca, Philip Ross Bullock. „Introduction”. Russia in Britain 1880-1940: from Melodrama to Modernism. Red. Rebecca Beasley, Philip Ross Bullock. Oxford, Oxford University Press, 2013, s. 1-18.

Benson, Jackson J. The True Adventures of John Steinbeck, Writer. New York, The Viking Press, 1984. Bullock, Phillip Ross. „Tsar's Hall: Russian Music in London 1895-1926”. Russia in Britain, 1880 1940: from Melodrama to Modernism. Red. Rebecca Beasley, Philip Ross Bullock. Oxford, Oxford University Press, 2013, s. 113-128.

Chatterjee, Choi, Beth Holmgren, red. American Experience of Russia: Encountering the Enigma, 1917 to the Present. New York-London, Routledge, 2013.

Crankshaw, Edward. Russia and the Russians. New York, The Viking Press, 1948.

Engerman, David C. „Studying Our Nearest Oriental Neighbor: American Scholars and Late Imperial Russia". American Experience of Russia: Encountering the Enigma, 1917 to the Present. Red. Choi Chatterjee, Beth Holmgren. New York-London, Routledge, 2013.

Feuer, Lewis. „American Travelers to the Soviet Union, 1917-1932: The Formation of a Component of New Deal Ideology”. American Quarterly, Summer, 1962.

Glotov, Oleksandr, Nataliâ Kolesnikova. „Džon Stejnbek v ocìncì rosìjs'kogo postradâns'kogo lìteraturoznavstva”. Zarubižna literatura, 7-8, 2006, s. 30-32.

Gumbol'dt, Vil'gel'm fon. Âzyk i filosofiâ kul'tury. Moskva, Progress, 1985.

Hingley, Ronald. The Russian Mind. New York, Charles Soribner's Sons, 1977.

Hollander, Paul. Political Pilgrims: Western Intellectuals in Search of the Good Society. New Brunswick-London, Transaction Publishers, 1998.

Holmgren, Beth. „Russia on Their Mind: How Hollywood Pictured the Soviet Front”. American Experience of Russia: Encountering the Enigma, 1917 to the Present. Red. Choi Chatterjee, Beth Holmgren. New York-London, Routledge, 2013.

Levontina, Irina. „Pomiloserdujte, bratcy!”. Klûčevye idei russkoj âzykovoj kartiny mira. Red. Anna Zaliznâk, Irina Levontina, Aleksej Shmelev. Moskva, Âzyki slavânskoj kul'tury, 2005, s. $270-279$.

Levontina, Irina. „Slovarnaâ stat'â «Žalost'»”. Novyj ob"âsnitel'nyj slovar' sinonimov russkogo âzyka. Red. Ûrij Apresân. Moskva, Âzyki slavânskoj kul'tury, 2003, s. 327-331.

Losskij, Nikolaj. Harakter russkogo naroda. Frankfurt am Main, Posev, 1957.

Nicolson, Nigel, Joanne Trautman, red. The Letters of Virginia Woolf. Vol. 3: 1923-1928, letter 1520. San Diego-New York, Harcourt Brace Jovanovich, 1977.

Pozner, Vladimir. „Predislovie”. Džon Stejnbek. Russkij dnevnik. Fotografii Roberta Kapy. Per. Evgenij Kručina. Moskva, Eksmo, 2017, s. 1.

Prohorov, Ûrij, Iosif Sternin. Russkie: kommunikativnoe povedenie. Moskva, Flinta. Nauka, 2006.

Protopopova, Dar'â. Virginia Woolf's Portraits of Russian Writers. Cambridge, Cambridge Scholars Publishing, 2019.

Protopopova, Dar'â. „Virginia Woolf's Versions of Russia”. Postgraduate English, issue 13, March 2006, s. 1-32.

Reinhold, Natalya. „Virginia Woolf's Russian Voyage Out”. Woolf Studies Annual, 9, 2003, s. 1-27. Rejngol'd, Nataliâ. „Russkaâ tema i obraz Rossii v tvorčestve Virdžinii Vulf”. Rossiâ i russkie v hudožestvennom tvorčestve zarubežnyh pisatelej XVII - načala XX-h vekov. Materialy kruglogo stola v IMLI im. A.M. Gor'kogo RAN (5 dekabrâ 2006 goda). Web. 06.07.2007. http:// www.nrgumis.ru/articles/99/.

Rubenstein, Roberta. Virginia Woolf and the Russian Point of View. New York, Palgrave Macmillan, 2009. 
Shillinglaw, Susan. „Introduction”. John Steinbeck. A Russian Journal with Photographs by Robert Capa. New York, Penguin, 1999.

Šillinglou, S'ûzen. „Predislovie”. Džon Stejnbek. Russkij dnevnik. Fotografii Roberta Kapy. Per. Evgenij Kručina. Moskva, Eksmo, 2017, s. 1-7.

Šmelev, Aleksej D. „Leksičeskij sostav russkogo âzyka kak otraženie «russkoj duši»”. Klûčevye idei russkoj âzykovoj kartiny mira. Red. Anna Zaliznâk, Irina Levontina, Aleksej Šmelev. Moskva, Âzyki slavânskoj kul'tury, 2005, s. 25-38.

Solov'ev, Vladimir. Tajny russkoj duši. Voprosy. Otvety. Versii. Moskva, Russkij âzyk. Kursy, 2001.

Stejnbek, Džon. Russkij dnevnik. Fotografii Roberta Kapy. Per. Evgenij Kručina. Moskva, Eksmo, 2017. Elektronnaâ Biblioteka LoveRead.ec. Web. 07.09.2019. http://loveread.ec/view_global. php?id=61607.

Stepanov, Ûrij. Konstanty. Slovar' russkoj kul'tury. Opyt issledovaniâ. Moskva, Âzyki russkoj kul'tury, 1997.

White, William Chapman. These Russians. New York, C. Scribne's Sons, 1931.

Wierzbicka, Anna. Semantics, Culture, and Cognition. Universal Human Concepts in Culture - Specific Configurations. New York-Oxford, Oxford University Press, 1992.

Woolf, Virginia. „The Russian Point of View”. Web. 23.08.2019. https://ebooks.adelaide.edu.au/w/ woolf/virginia/w91c/chapter16.html. 